\title{
ON THE MICROSTRUCTURE CHARACTERIZATION OF THE AL6082-AISI304 ALLOYS WELDED BY FSW
}

\author{
${ }^{1}$ Ciprian Pavel LUCIAN, ${ }^{2}$ Olimpiu KARANCSI, ${ }^{3}$ Ion MITELEA, ${ }^{4}$ Ion-Dragoş UŢU, \\ ${ }^{5}$ Corneliu-Marius CRĂCIUNESCU \\ 1,3,4,5 Politehnica University of Timişoara, Timişoara, Romania, EU, \\ ${ }^{1}$ ciprian.lucian@student.upt.ro, ${ }^{3}$ ion.mitelea@upt.ro, ${ }^{4}$ dragos.utu@upt.ro, ${ }^{5}$ corneliu.craciunescu@upt.ro \\ ${ }^{2}$ Victor Babeş University of Medicine and Pharmacy, Timişoara, Romania, EU, olilk@yahoo.com
}

\section{https://doi.org/10.37904/metal.2021.4224}

\begin{abstract}
Welding of aluminum alloys with austenitic stainless steel is considered one of the most complex phenomena and is specific to high precision industries such as: aerospace, rail, cars and marine structures, as inflexible tolerance are required during the assembly of various engineering components. Joining of such alloys through conventional fusion welding processes is a difficult task because of the metallurgical incompatibility. On the other hand, friction stir welding (FSW) with rotary tool of this two materials, has given rise to substantial scientific and industrial importance, as it has the capacity to manufacture products with good quality joints. This paper aims to highlight the benefits of the FSW process applied to this combination of materials. A particular attention is given to the microstructural evolution and microhardness in the transition areas between the austenitic stainless steel and the welding core.
\end{abstract}

Keywords: Friction stir welding, dissimilar alloys, microstructure

\section{INTRODUCTION}

FSW is a solid state process that is capable of generating high quality reproducible welded joints of similar aluminum-based alloys $[1,6]$ and dissimilar materials $[2,5,6]$. In case of this FSW process, a tool provided with a cylindrical shoulder and a profiled pin is rotated and plunged in the joint area of the two components of material delivered in the form of sheet metal or plate [1]. The heat developed as a result of friction between the active element and the components to be welded, gives rise to a concentric zone of material that softness without reaching the melting temperature. By moving the tool along the welding line, the plasticized material is transferred to the rear edge of the tool pin and is forged by the intimate contact with the tool shoulder and the pin profile. Upon cooling, a solid phase connection is created between the parts [1,2]. Compared to conventional fusion welding methods, the FSW process offers a number of advantages such as: low energy consumption, short welding time, low distortions and relatively low welding temperatures. The factors that define the quality of welded joints with rotating active element are:

- $\quad$ Shape and dimension of the rotating active element;

- Tool rotation speed;

- Welding advancing speed;

- $\quad$ Pressing force;

- Nature and characteristics of the materials to be welded.

The main potential applications of this process are the aircraft constructions, high speed trains manufacture welding of fuel tanks in the aerospace industry, automotive industry etc. [3, 4]. The objective of this research 
is to evaluate the performance of heterogeneous FSW joints between age-hardenable aluminum alloys and austenitic stainless steel with a low carbon content. The assessment of the quality of heterogeneous welded joints was made by metallographic investigations and microhardness measurements.

\section{EXPERIMENTAL PROGRAM}

The experimental works were conducted on a specialized friction welding machine with rotating active element. By preliminary test, the optimal welding regime was established, characterized by the parameters indicated in the Table 1.

Table 1 Regime parameters of welding process

\begin{tabular}{|c|c|c|c|c|c|c|}
\hline \multirow{2}{*}{$\begin{array}{l}\text { Nr. } \\
\text { crt. }\end{array}$} & \multirow{2}{*}{$\begin{array}{c}\text { Material } \\
\text { combination }\end{array}$} & \multicolumn{2}{|c|}{ Materials thickness $(\mathrm{mm})$} & \multirow{2}{*}{$\begin{array}{l}\text { Welding } \\
\text { speed } \\
(\mathrm{mm} / \mathrm{min})\end{array}$} & \multirow{2}{*}{$\begin{array}{l}\text { Tool revolution } \\
(\text { rot } / \mathrm{min})\end{array}$} & \multirow{2}{*}{$\begin{array}{l}\text { Welding tool } \\
\text { material }\end{array}$} \\
\hline & & Steel & Al alloy & & & \\
\hline 1 & Al 6082 - AISI 304 & 5 & 5 & 60 & 700 & WC \\
\hline
\end{tabular}

To prevent the aluminum alloy overheating, the tool pin was moved to the aluminum plate so that the stirring action of the pin was mainly directed towards this component. Vickers microhardness test and metallographic analyzes were performed on the welded joints using the optical microscope and the scanning electron microscope.

\section{DISCUSSION OF EXPERIMENTAL RESULTS}

\subsection{Structural characteristics}

Figure 1 shows the macroscopic image of a cross section through the FSW joint of the two dissimilar metal alloys. Unlike the FSW of similar aluminum alloys [5,6], welds of dissimilar materials have several distinct areas, namely: (a) base metal-stainless steel, (b) heat affected zone (HAZ) in stainless steel at the weld advance side, (c) thermomechanically affected zone, (TMAZ) in stainless steel at the weld advance side, (d) weld nugget, (e) thermomechanically affected zone, (TMAZ) in aluminum alloy at the shrinkage of the weld, ( $f$ ) heat affected zone (HAZ) in aluminum alloy at the shrinkage of the weld and (g) the base metal - Al alloy.

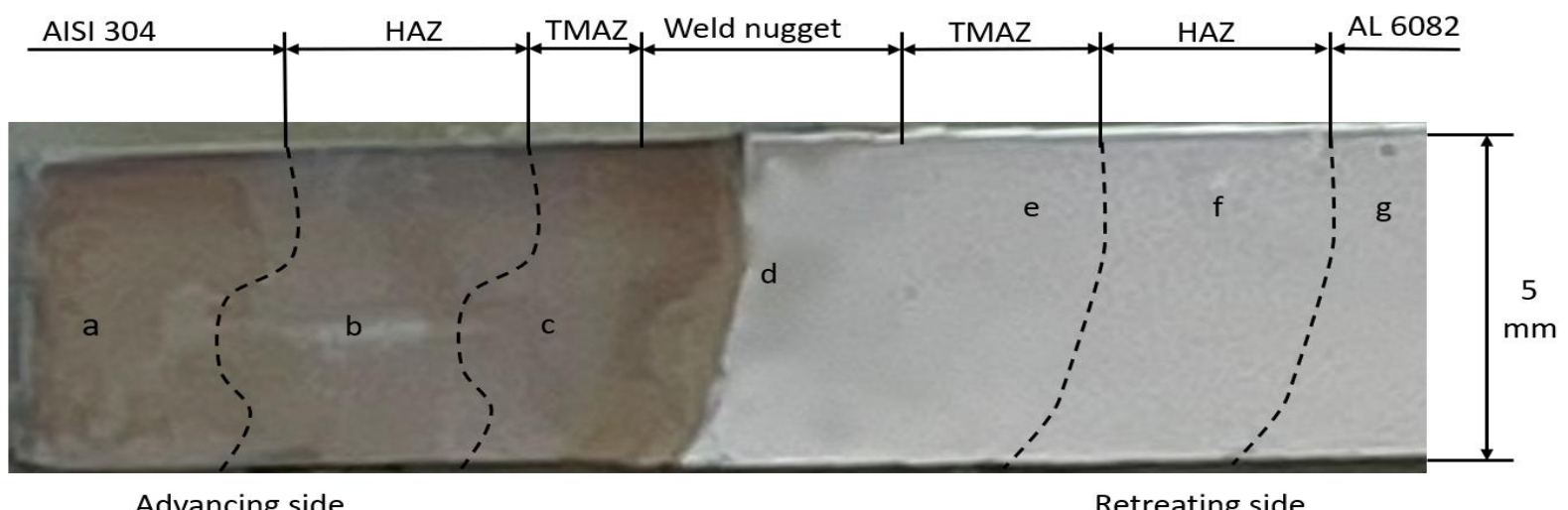

Figure 1 Macrograph of a cross section through the FSW joint

The optical micrographs of these regions from Figure $\mathbf{1}$ are shown in Figures $\mathbf{2}$ to $\mathbf{5}$. The stainless steel base metal has a microstructure consisting of austenite grains with a small proportion of ferrite $\delta$ and $\mathrm{Cr}_{23} \mathrm{C}_{6}$ complex carbides (Figure 2). The HAZ microstructure of the stainless steel in the advancing side is almost similar to that of the base metal, not thermomechanically affected (Figure 3). In the thermomechanically affected area of stainless steel, the presence of a certain proportion of phase $\sigma$ is observed (Figures 4 and 5). Normally, 
this chromium rich intermetallic compound, with pronounced hardness and fragility, occurs by applying thermal aging treatments to ferritic, austenitic and duplex stainless steels. Although its separation from austenite requires long periods of time [7], in the case of FSW processing, its formation will be accelerated by the transformation of the austenite into ferrite $\delta$ at high temperature reached during the process and the subsequent decomposition of ferrite underhigh speed plastic deformation and a recrystallization induced through agitation by friction. Figures $\mathbf{4}$ and $\mathbf{5}$ show that the precipitation of the $\sigma$ phase takes places mostly on the boundaries of ferrite grains and on the interface between ferrite and austenite. The precipitation potential of the $\sigma$ phase in regions rich in chromium (meaning in ferrite $\delta$ ) was estimated to be approx. 100 times higher than in the austenite regions[7].

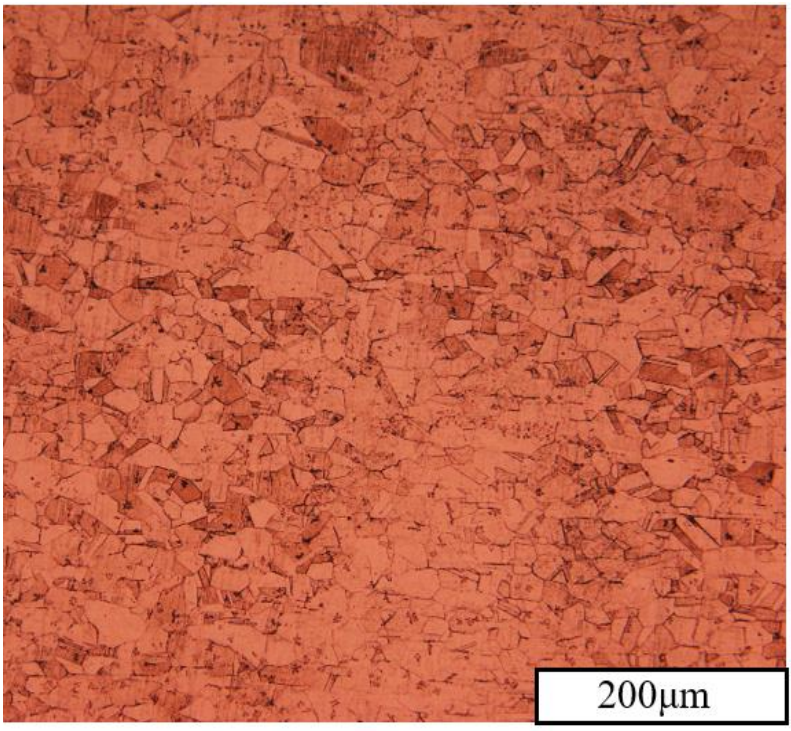

Figure 2 Microstructure of base metal stainless steel

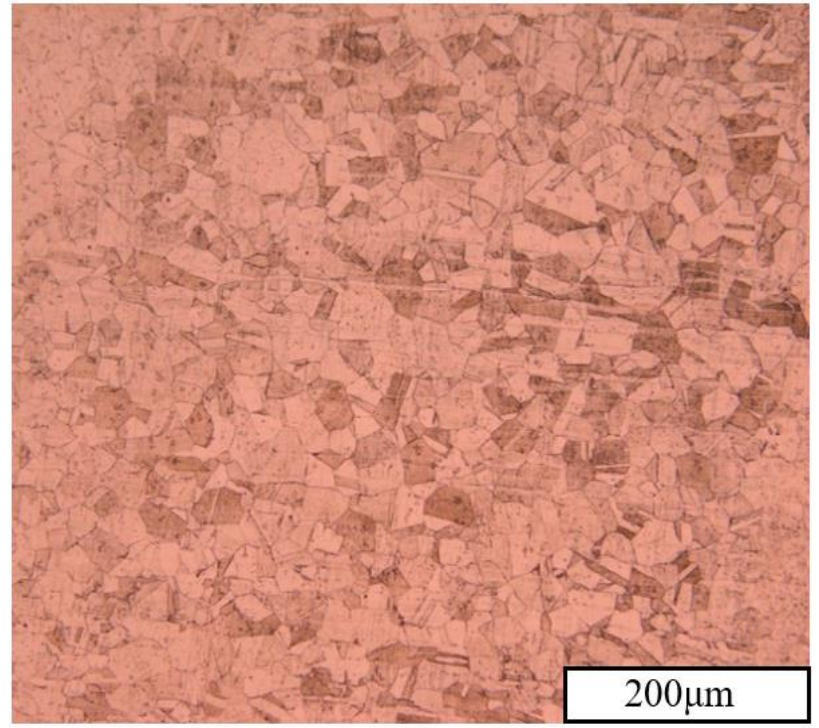

Figure 3 Stainless steel HAZ microstructure

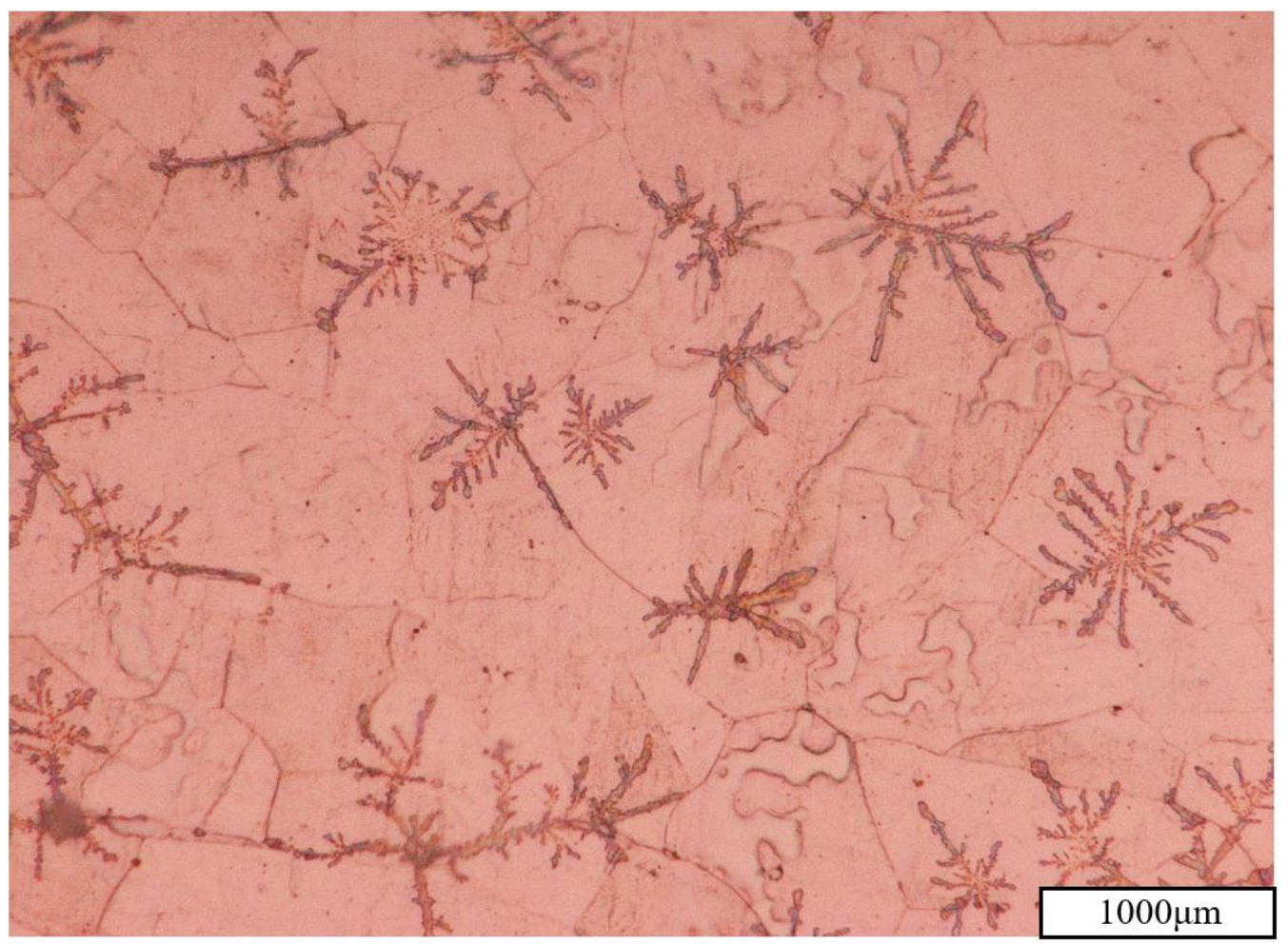

Figure 4 Stainless steel microstructure in the thermomechanically affected zone 

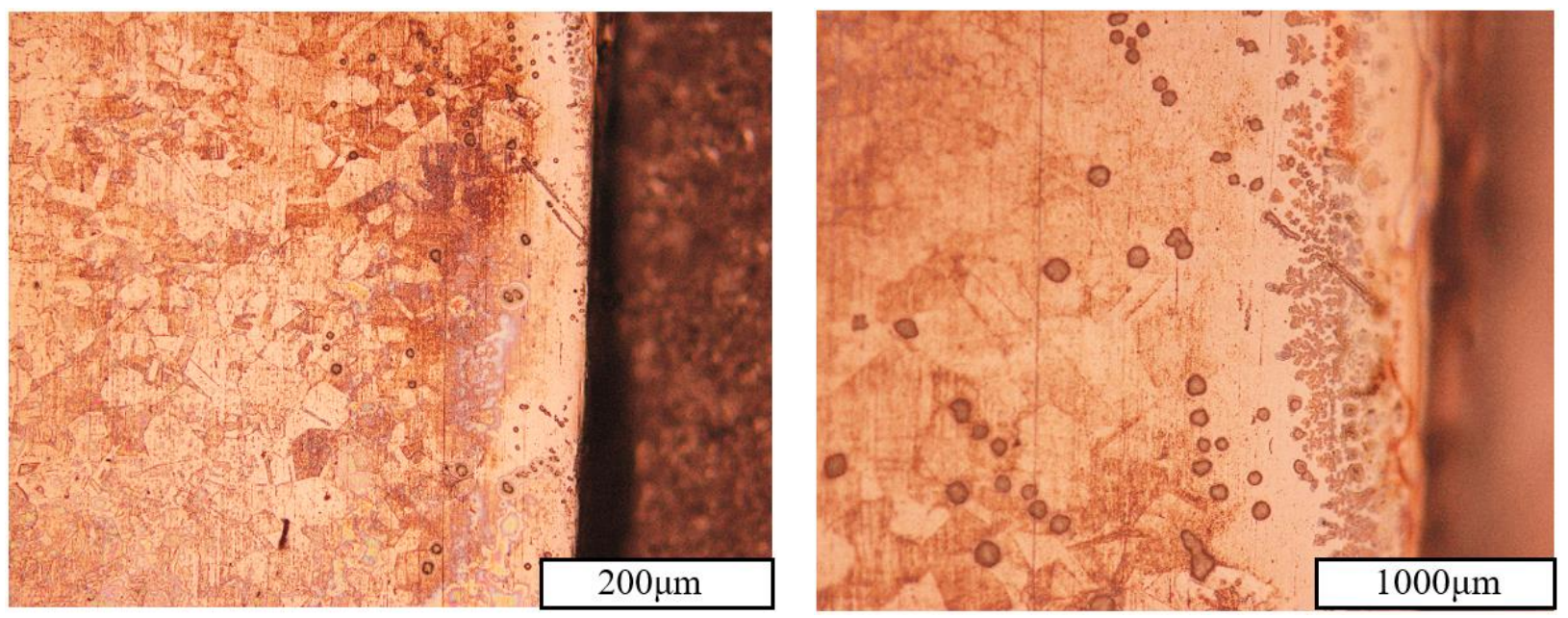

Figure 5 Stainless steel microstructure in the area of the interface with the weld nugget

The weld nugget corresponds approximately to the location of the pin during welding and is a strongly deformed material in which thin strips mixed with softer material are observed (Figure 6). This was formed after mixing the Al alloy with stainless steel particles extracted from the surface of the stainless steel by the forging action that characterizes the joining process (Figures 6,7). Therefore, the weld nugget has a structure composed of Al 6082 alloy reinforced with stainless steel particles. These particles have an irregular shape and an uneven distribution in the welding core (Figure 7). The Al alloy in the weld nugget consist of fine, equiaxial grains (Figure 6), obtained by recrystallization annealing of the strongly deformed material and which have a size of approx. 10-15 $\mu \mathrm{m}$, much smaller than that of base material.

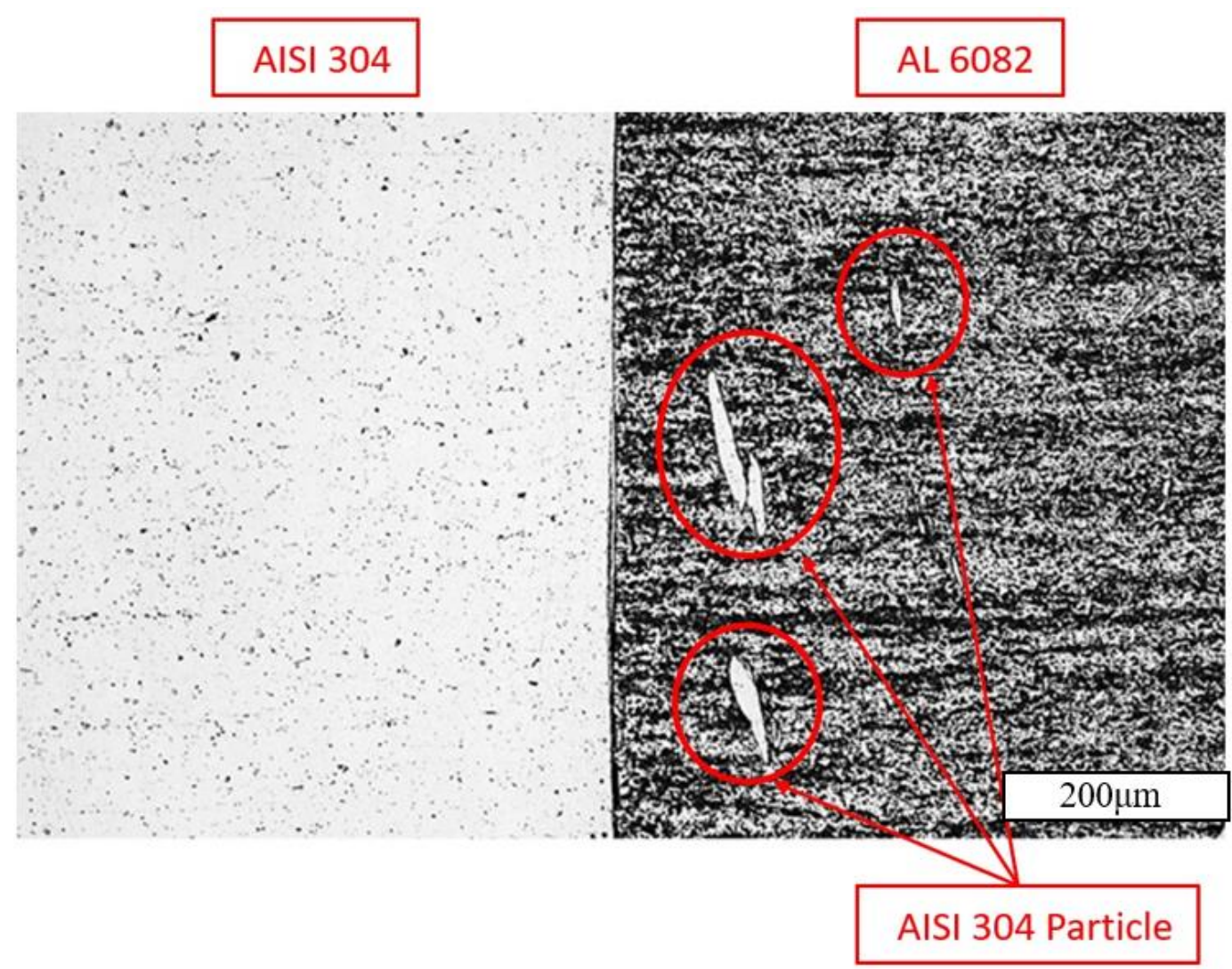

Figure 6 Structural image of a section through welded joint 


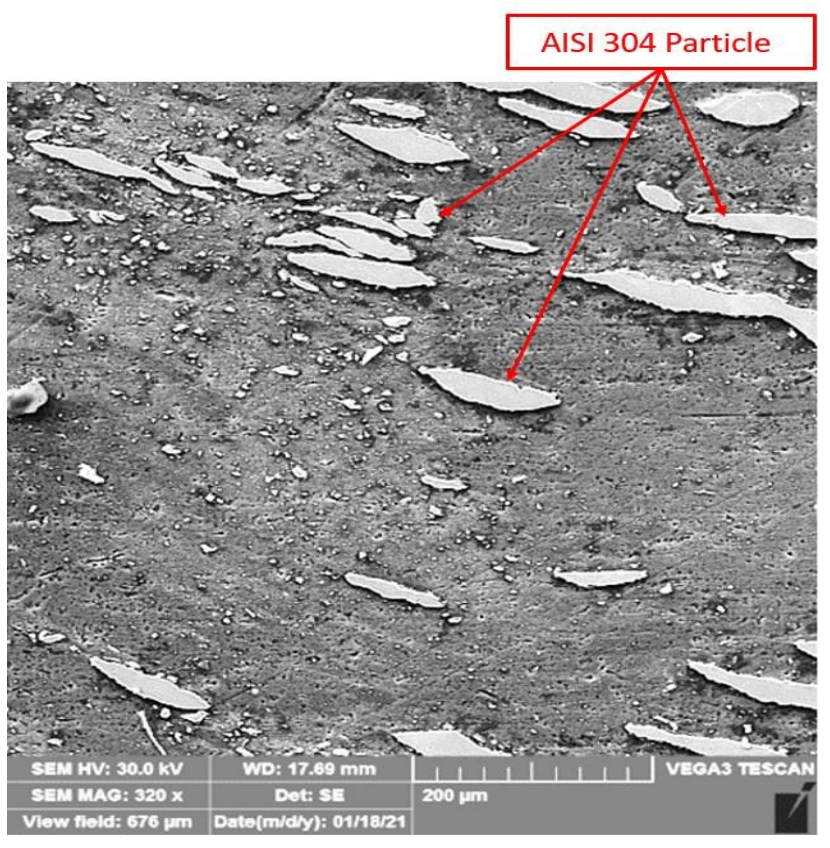

Figure 7 Weld nugget SEM microstructure

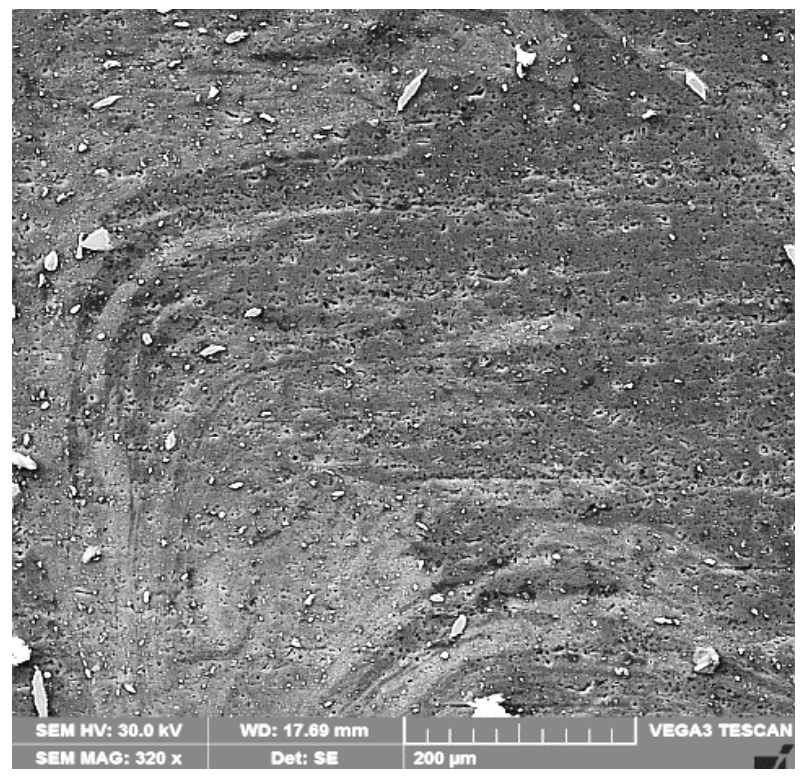

Figure 8 TMAZ SEM image of Al alloy

The thermomechanically affected zone, TMAZ, adjacent to the weld nugget on the retreating side, is characterized by a rotation of up to $90^{\circ}$ of the elongated grains of the Al based alloy (Figure 8). As a result of the deformation process, several concentric rings are formed, which have been named as "onion rings“ type structure (Figure 8). Between TMAZ and the unaffected base metal of aluminum alloy from the retreating side, a heat affected zone HAZ appears, characterized by lower temperaturesin which slight over aging phenomena are manifested. The base metal of Al alloy contains elongateddeformed grains and fine particles of intermetallic compounds (Figure 9).

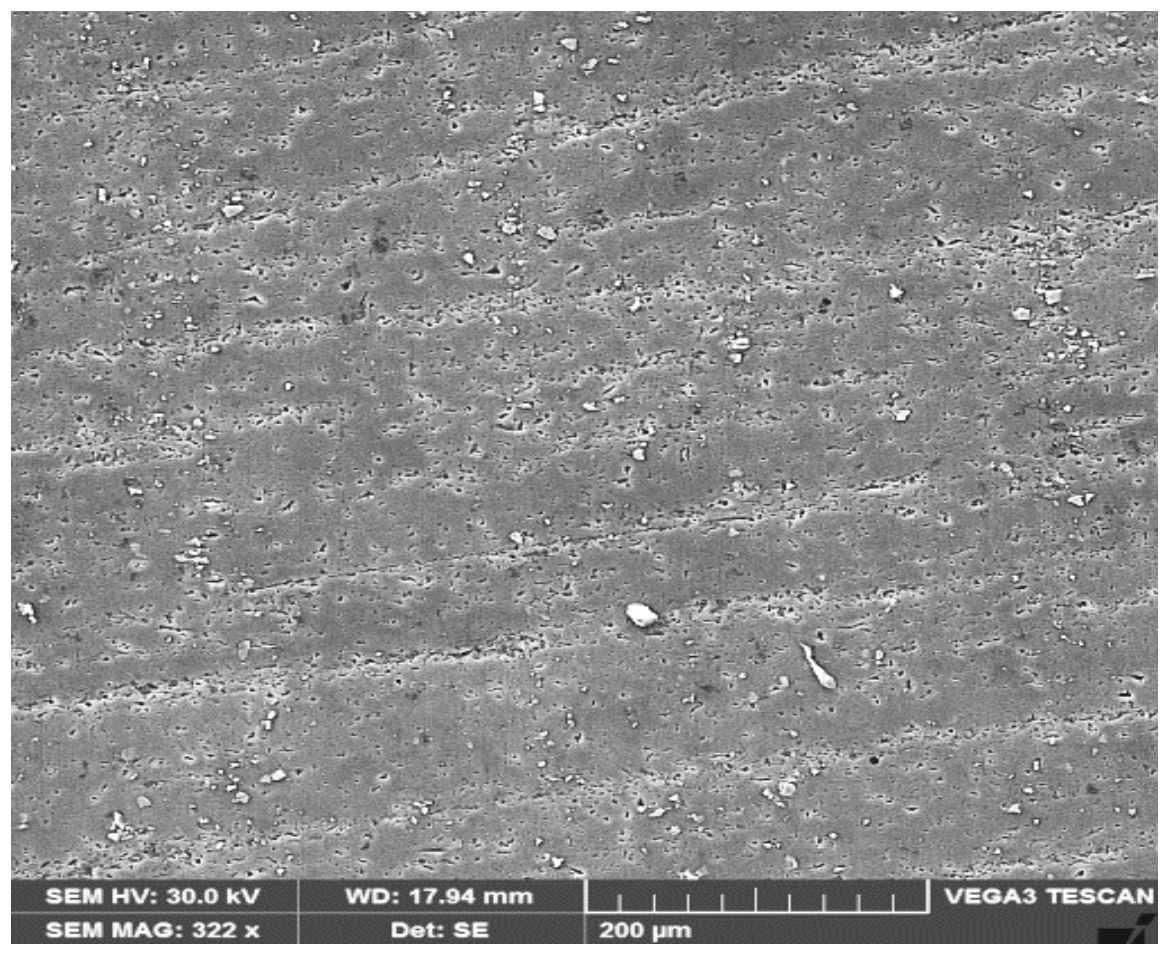

Figure 9 SEM micrograph of aluminum alloy 


\subsection{Microhardness tests}

Experimental measurements showed that the weld nugget has an average hardness of approx. 110-120HV, which is lower than that of the austenitic stainless steel base metal (190-200HV). As a result of the uneven distribution of the stainless steel particles in the weld nugget, variable hardness values appeared, depending on the point where the measurement was performed. In TMAZ on the advancing side (Al 6082 alloy side) the hardness decreases slightly, to values of $90-100 \mathrm{HV}$, as a result of the dissolution of the secondary phase particles. This reduction in hardness is specific to HAZ of AL6082 alloy and is justified by the dissolution of all secondary phase precipitates. The slight decrease in the hardness values in HAZ of the stainless steel (180$190 \mathrm{HV}$ ) in the advancing side, indicates that there is not a sufficiently high temperature during welding for microstructural changes to take place. However, an increase in hardness was observed in the upper weld area (230-235 HV), which could be attributed to the work hardening of the austenitic stainless steel.

\section{CONCLUSION}

The FSW technique is suitable for joining deformable aluminum alloys with austenitic stainless steels with a low carbon content. The microstructure of the FSW joints between the two dissimilar materials contains several characteristic areas determined by the temperature level, the degree of deformation reached and the time elapsed between the peak temperature and the thermal recrystallization threshold. The presence of stainless steel particles in the weld nugget justifies the variable values of its microhardness. In the upper part of thermomechanically affected zone of stainless steel an increase of the microhardness due to thework hardening effect is produced. The hardness value decreases slightly in TMAZ at the advancing side (Al 6082T6 alloy side). The minimum hardness appears in the HAZ of the Al 6082-T6alloy at a distance of approx. 6$11 \mathrm{~mm}$ from the centre of the weld on the retraction side.

\section{REFERENCES}

[1] THOMAS, W.N., NICHOLAS, E.D., NEEDHAM, J.D., MURCH, M.G., TEMPLESMITH, P., DAWS, C.J. GB Patent Application 9125978.8, Dec. 1991, US Patent Application 5460317, Oct.1995.

[2] MISHRA, R.S, MA, Z.Y. Friction stir welding and processing. Materials Science and Engineering. 2005, vol. 50, pp. 1-78.

[3] BUCHIBABU, V., REDDY, G.M., KULKARNI, D.V., DE, A. Welding of a thick Al-Zn-Mg alloy plate. Journal of Materials Engineering and Performance. 2016, vol. 25, no. 3, pp. 1163-1171.

[4] LEE, W.B., YEON, Y.M., KIM, D.U., JUNG, S.B. Effect of friction welding parameters on mechanical and metallurgical properties of aluminum alloy 5052-A36 steel joint. Mater. Sci. Technol. June 2003, vol. 19, pp. 773778.

[5] BARCELLONA, A., BUFFA, G., FRATINI, L., PALMERI, D. On microstructural phenomena occurring in friction stir welding of aluminum alloys. Journal of Materials Processing Technology. 2006, vol. 177, pp. 340-343.

[6] SALEM, H.G. Friction stir weld evolution of dynamically recrystallized AA2095 weldments. Scripta Materialia. 2003, vol. 49, pp. 1103-1110.

[7] SEUNG HWAN, C.P., YUTAKA, S.S, HIROYUKI, K., KAZUTAKA, O. Rapid formation of the sigma phase in 304 stainless steel during friction stir welding. Scripta Materialia. 2003, vol. 49, no. 12, pp.1175-1180. 